\title{
Audiovestibular profile of patients attending Audiology unit of Al-Hussin University Hospital
}

\begin{abstract}
Mostafa Mohamed Bastaweesy ${ }^{1}$ M.B.B.CH; Ali Abdel Daiem Ali Azab ${ }^{2}$ MD; Mohammad Sayed Ali ${ }^{2}$ MD.
\end{abstract}
* Corresponding Author:

Mostafa Mohamed Bastaweesy mostafabastaweesy111@gmail.com

Received for publication Septemper 5, 2021; Accepted November 8, 2021; Published online November 8, 2021.

Copyright The Authors
published by Al-Azhar
University, Faculty of Medicine,
Cairo, Egypt. Users have the
right to read, download, copy,
distribute, print, search, or link
to the full texts of articles under
the following conditions:
Creative Commons Attribution-
Share Alike 4.0 International
Public License (CC BY-SA 4.0).
doi: 10.21608/aimj.2021.92924.1560
${ }^{1}$ Unit of Audiovestibular Medicine,
ENT Department, Kobry El-Kobba
Military Hospital, Egypt, Cairo,
Egypt.
${ }^{2}$ Unit of Audiovestibular Medicine,
ENT Department, Faculty of
Medicine, Al-Azhar University,
Cairo, Egypt.
\begin{abstract}
Background: Hearing loss can be categorized as a conductive, sensorineural, or mixed hearing loss based on the anatomic location of the problem. A hearing loss may also be considered unilateral or bilateral. Dizziness and vertigo are common clinical complaints. A disturbed vestibular system causes vertigo.

Aim of the study: Study the profile of patients based on various variables and compare retrospective and prospective profiles of patients attending the Audiovestibular unit at Al-Hussin University Hospital.

Patients and Methods: This study was conducted on 1868 subjects who attended the Unit of Audiovestibular Medicine at Al-Hussin University Hospital from 1/7/2016 to31/12/2016, then from1/1/2017 to 30/6/2017. The purpose was to determine the hearing and vestibular conditions for these subjects. The study was divided into two parts retrospective and prospective parts.

Results: There was a statistically significant difference between different HL types among different age groups, with the adults and subjects above 60 years have a higher hearing impairment. In this study, the highest incidence of vestibular disorders is found in adult group (16.2\%) cases followed by the old age group (10.8\%) cases then preschool and child group $(1.2 \%)$ cases.

Conclusion: The frequent causes of hearing impairment were presbycusis, noise exposure, wax, and otitis media. Benign paroxysmal positional vertigo (BPPV) was the commonest cause of vertigo in this study. The adult and old age groups had the highest incidence of hearing impairment and vertigo in this study.
\end{abstract}

Keywords: Hearing; Vertigo; Sensorineural; Conductive Hearing Loss.

Disclosure: The authors have no financial interest to declare in relation to the content of this article. The Article Processing Charge was paid for by the authors.

Authorship: All authors have a substantial contribution to the article.

\section{INTRODUCTION}

Based on the anatomic site of the problem, the hearing loss can be characterized as conductive, sensorineural, or mixed. A hearing loss can either be unilateral or bilateral. The degree of loss could be either symmetrical or asymmetrical. ${ }^{1}$

Sensorineural hearing loss (SNHL)is caused by lesions of the cochlea, 8th nerve, and/or central auditory pathways. The cochlea, cranial nerve (CN.) VIII, brainstem, and/or temporal lobe are all involved in the development of SNHL. They can be congenital, traumatic, infectious, inflammatory, iatrogenic, neoplastic, senile, or a variety of other conditions. $^{2}$

Obstructing air conduction causes conductive hearing loss, preventing sound waves from properly transmitting through the external auditory canal 
Vertigo and unsteadiness are two of the most prevalent clinical complaints. A malfunctioning vestibular system causes vertigo. It is divided into peripheral vertigo (up to the vestibular nuclei) and central vertigo (due to vestibular nerve or central connections to the brainstem and cerebellum failure). ${ }^{5}$

This study aimed to examine the profile of patients based on various variables and compare retrospective and prospective profiles of patients attending the Audiology unit at Al-Hussin University Hospital.

\section{PATIENTS AND METHODS}

This study was conducted on all patients attending the Audiovestibular unit of Al-Hussin University Hospital between $1 / 7 / 2016$ to $31 / 12 / 2016$ as a retrospective part of the study (group 1) and from $1 / 1 / 2017$ to $30 / 6 / 2017$ as the prospective portion of the study (group 2). Age, gender, history, complaint, type of hearing loss, degree of hearing loss, and vestibular exam were used to categorize all subjects.

Two-channel audiometer Interacoustics AC40, immittance meter GSI 39, auditory brainstem response (ABR) models HIS, and Four channels VNG-Micromedical Technology version 4 were used.

Patients included in the study were subjected to the following: Full medical history, otological examination, and basic audiological evaluation, including pure tone audiometry in the form of Air

conduction threshold determination at the following frequencies (250-500-1000-2000-4000-8000) Hz and Bone conduction threshold determination at the following frequencies (500-1000-2000-4000) Hz, speech audiometry in the form of speech reception threshold (SRT) determination using Arabic spondee words and word discrimination score (WDS) determination using Arabic PB words at $40 \mathrm{~dB}$ sensation level (ref SRT) or the most comfortable level, auditory brainstem response (ABR) if needed and videonystagmography (VNG) test battery.

The study protocol had been submitted for approval by Al-Azhar University's Institutional Review Board, informed verbal consent had been obtained from all participants in the study, and confidentiality and individual privacy had been protected at all stages of the study.

Data were analyzed statistically using the Statistical Program for Social Science (SPSS) version 24. Quantitative data were expressed as mean \pm SD (for normally distributed data), median-IQR (for abnormally distributed data) (for abnormally distributed data). Qualitative data were expressed as frequency and percentage.

\section{RESULTS}

\begin{tabular}{|lllll|}
\hline \hline Age (years) & Group 1 & Group 2 & T test & p-value \\
\hline Mean \pm SD & $36.7 \pm 19.8$ & $37.8 \pm 20.4$ & 0.7 & 0.4 \\
\hline
\end{tabular}

Table 1: Age distribution among studied groups. There is no statistically significant difference between the two groups (p-value > 0.05). Group 1 (retrospective), Group 2 (prospective).

\begin{tabular}{lll}
\hline Gender & No. $($ Total $=\mathbf{1 8 6 8})$ & Percent $(\boldsymbol{\%})$ \\
\hline Male & 950 & $50.9 \%$ \\
Female & 918 & $49.1 \%$ \\
\hline
\end{tabular}

Table 2: Gender distribution among all studied patients.

\begin{tabular}{|c|c|c|c|c|c|c|}
\hline Main complaint & $\begin{array}{l}\text { Preschool } \\
\text { No. }(\%)\end{array}$ & $\begin{array}{l}\text { Child } \\
\text { No. (\%) }\end{array}$ & $\begin{array}{l}\text { Adult } \\
\text { No. (\%) }\end{array}$ & $\begin{array}{l}\text { Old Age } \\
\text { No. }(\%)\end{array}$ & Test & $\mathbf{P}$ \\
\hline Hearing loss & $\begin{array}{l}40 \\
(4.3 \%)\end{array}$ & $\begin{array}{l}166 \\
(17.9 \%)\end{array}$ & $\begin{array}{l}490 \\
(52.9 \%)\end{array}$ & $\begin{array}{l}230 \\
(24.8 \%)\end{array}$ & \multirow[t]{6}{*}{$\begin{array}{l}\chi 2= \\
207\end{array}$} & \multirow[t]{6}{*}{0.001} \\
\hline Discharge & $\begin{array}{l}30 \\
(23.8 \%)\end{array}$ & $32(25.4 \%)$ & $\begin{array}{l}62 \\
(49.2 \%)\end{array}$ & (1.6\%) & & \\
\hline Tinnitus & $\begin{array}{l}0 \\
(0 \%)\end{array}$ & $\begin{array}{l}10 \\
(2.9 \%)\end{array}$ & $\begin{array}{l}284 \\
(83.5 \%)\end{array}$ & $\begin{array}{l}46 \\
(13.5 \%)\end{array}$ & & \\
\hline Earache & $\begin{array}{l}10 \\
(9.3 \%)\end{array}$ & $\begin{array}{l}110 \\
(50.9 \%)\end{array}$ & $\begin{array}{l}82 \\
(38 \%)\end{array}$ & $\begin{array}{l}4 \\
(1.9 \%)\end{array}$ & & \\
\hline Headache & $\begin{array}{l}0 \\
(0 \%)\end{array}$ & $10(16.1 \%)$ & $\begin{array}{l}50 \\
(80.6 \%)\end{array}$ & $\begin{array}{l}2 \\
(3.2 \%)\end{array}$ & & \\
\hline Vertigo & $\begin{array}{l}0 \\
(0 \%)\end{array}$ & $\begin{array}{l}6 \\
(3 \%)\end{array}$ & $\begin{array}{l}152 \\
(76.8 \%)\end{array}$ & $\begin{array}{l}40 \\
(20.2 \%)\end{array}$ & & \\
\hline
\end{tabular}

Table 3: Main complaint distribution among different age groups. Hearing loss, tinnitus, then earache, and vertigo were the predominant complaint among different age groups. Adults and the elderly reported the majority of complaints. Ear discharge and headache were less common. 


\begin{tabular}{lllllll}
\hline HL Type & Preschool & Child & Adult & Old Age & Test & P \\
& No. $(\%)$ & No. $(\%)$ & No. $(\%)$ & No. $(\%)$ & & \\
\hline No HL & 6 & 74 & 232 & 8 & $\chi 2=231$ & 0.001 \\
& $(0.3 \%)$ & $(4 \%)$ & $(12.4 \%)$ & $(0.4 \%)$ & & \\
CHL & 24 & 124 & 246 & 10 & & \\
& $(1.3 \%)$ & $(6.6 \%)$ & $(13.2 \%)$ & $(0.5 \%)$ & & \\
SNHL & 30 & 114 & 444 & 182 & & \\
& $(1.6 \%)$ & $(6.1 \%)$ & $(23.8 \%)$ & $(9.7 \%)$ & & \\
MHL & 28 & 22 & 200 & 124 & & \\
& $(1.4 \%)$ & $(1.2 \%)$ & $(10.7 \%)$ & $(6.6 \%)$ & & \\
& & & & &
\end{tabular}

Table 4: Hearing loss type distribution among different age groups. A statistically significant difference was found between different percentages of HL types among different age groups with predominant all HL types in the adult age group (p-value < 0.05 ).

\begin{tabular}{lllllll}
\hline Immittancy type & $\begin{array}{l}\text { Preschool } \\
\text { No. }(\%)\end{array}$ & $\begin{array}{l}\text { Child } \\
\text { No. }(\%)\end{array}$ & $\begin{array}{l}\text { Adult } \\
\text { No. }(\%)\end{array}$ & $\begin{array}{l}\text { Old age } \\
\text { No. }(\%)\end{array}$ & Test & P \\
\hline A & 100 & 150 & 580 & 350 & $\chi 2=353.7$ & 0.001 \\
& $(5.3 \%)$ & $(8.1 \%)$ & $(31.1 \%)$ & $(18.7 \%)$ & & \\
B & 80 & 120 & 54 & 40 & & \\
& $(4.3 \%)$ & $(6.4 \%)$ & $(2.9 \%)$ & $(2.1 \%)$ & & \\
C & 34 & 70 & 20 & 10 & & \\
& $(1.8 \%)$ & $(3.8 \%)$ & $(1.1 \%)$ & $(0.5 \%)$ & & \\
\hline
\end{tabular}

Table 5: Immittancy distribution among different age groups. A statistically significant difference was found between different age groups regarding immittancy type with predominant type b and c among child and preschool age groups (p-value $<0.05$ ).

\begin{tabular}{lllllll}
\hline HL Side & Preschool & Child & Adult & Old Age & Test & P \\
& No. $(\%)$ & No. $(\%)$ & No. $(\%)$ & No. $(\%)$ & & \\
\hline Unilateral & 6 & 70 & $382(20.4 \%)$ & 82 & $\chi 2=55.7$ & 0.001 \\
& $(0.3 \%)$ & $(3.7 \%)$ & & $(4.4 \%)$ & & \\
Bilateral & 46 & $190(10.2 \%)$ & $538(28.8 \%)$ & 234 & & \\
& $(2.5 \%)$ & & & $(12.5 \%)$ & & \\
\hline
\end{tabular}

Table 6: Hearing loss laterality distribution among different age groups. A statistically significant difference (pvalue < 0.05 ) was found between different HL sides among different age groups. All HL types were predominant in the adult age group and bilateral more than unilateral.

\begin{tabular}{|c|c|c|c|c|c|c|c|}
\hline \multirow[t]{2}{*}{ ABR } & \multicolumn{2}{|c|}{$\begin{array}{l}\text { Group 1 } \\
(\text { no.=930) }\end{array}$} & \multicolumn{2}{|c|}{$\begin{array}{l}\text { Group } \\
\text { (no.=938) }\end{array}$} & \multirow[t]{2}{*}{2} & \multirow[t]{2}{*}{ Test } & \multirow[t]{2}{*}{$\mathbf{P}$} \\
\hline & No. & $\%$ & No. & $\%$ & & & \\
\hline Normal & 24 & $1.3 \%$ & 2 & $0.1 \%$ & & \multirow[t]{2}{*}{$\chi 2=10.05$} & \multirow[t]{2}{*}{0.007} \\
\hline Abnormal & 94 & $4 \%$ & 84 & $4.5 \%$ & & & \\
\hline
\end{tabular}

Table 7: ABR distribution among studied groups. There was a statistically significant difference between different ABR groups ( $\mathrm{p}$-value $<0.05)$.

\begin{tabular}{lllllll}
\hline ABR & Preschool & Child & Adult & Old Age & Test & P \\
& No. $(\%)$ & No. $(\%)$ & No. $(\%)$ & No. $(\%)$ & & \\
\hline Normal & 2 & 22 & 2 & 0 & $\chi 2=231$ & 0.001 \\
& $(0.1 \%)$ & $(1.2 \%)$ & $(0.1 \%)$ & $(0 \%)$ & & \\
Abnormal & 48 & 94 & 36 & 0 & & \\
& $(2.6 \%)$ & $(5 \%)$ & $(1.9 \%)$ & $(0 \%)$ & & \\
\hline
\end{tabular}

Table 8: ABR distribution among different age groups. This table shows a statistically significant difference between ABR among different age groups with abnormal ABR among the adult age group and predominant abnormal ABR among the preschool and child age groups ( $\mathrm{p}$-value $<0.05$ ). 


\begin{tabular}{lllllll}
\hline VNG & Preschool & Child & Adult & Old Age & Test & P \\
& No. $(\%)$ & No. $(\%)$ & No. $(\%)$ & No. $(\%)$ & & \\
\hline Normal & 0 & 14 & $240(12.8 \%)$ & 54 & $\chi 2=231$ & 0.001 \\
& $(0 \%)$ & $(0.7 \%)$ & & $(2.9 \%)$ & & \\
Abnormal & 0 & 22 & 302 & 202 & & \\
& $(0 \%)$ & $(1.2 \%)$ & $(16.2 \%)$ & $(10.8 \%)$ & & \\
\hline
\end{tabular}

Table 9: VNG distribution among different age groups. There was a statistically significant difference (p-value < 0.05 ) between VNG among different age groups with abnormal VNG among the old and child age groups and predominant abnormal VNG among the adult age group.

\begin{tabular}{|c|c|c|c|c|c|c|}
\hline VNG & $\begin{array}{l}\text { Gro } \\
\text { (No. }\end{array}$ & & $\begin{array}{l}\text { Gro } \\
\text { (No. }\end{array}$ & & Stat. test & P-value \\
\hline Normal & 140 & $15 \%$ & 168 & $18.0 \%$ & \multirow[t]{2}{*}{$\chi 2=7.22$} & \multirow[t]{2}{*}{$0.027 \mathrm{~S}$} \\
\hline Abnormal & 250 & $26.8 \%$ & 276 & $29.4 \%$ & & \\
\hline
\end{tabular}

Table 10: Comparison between studied groups as regard VNG. There was a statistically significant difference (pvalue $<0.05$ ) between studied groups as regard VNG.

\begin{tabular}{|lll}
\hline Outcome & No. $($ Total $=\mathbf{1 8 6 8})$ & Percent $(\boldsymbol{\%})$ \\
\hline Medication & 928 & $49.7 \%$ \\
\hline Surgical intervention & 186 & $10 \%$ \\
\hline Rehabilitation & 754 & $40.4 \%$ \\
\hline
\end{tabular}

Table 11: Outcome among all studied patients. Among the patients studied, 928 (49.7\%) received medication, 754 $(40.4 \%)$ received a hearing and vestibular rehabilitation, and $186(10 \%)$ received surgical intervention.

\section{DISCUSSION}

This study was conducted on 1868 subjects who attended the Unit of Audiovestibular Medicine at AlHussin University Hospital from 1/7/2016 to $31 / 12 / 2016$, then from $1 / 1 / 2017$ to $30 / 6 / 2017$. The purpose was to determine the condition of hearing impairment and vestibular disorders for these subjects. The study was divided into two parts group 1(retrospective) and group 2 (prospective ).

The subjects conducted in this study included 950 males and 918 females; The mean age distribution of the first group (retrospective) was $36 \pm 19.8$, while the age distribution of the second group (prospective) was $37.8 \pm 20.4$, with no statistically significant difference between the two groups; this means that the rate of attendance of the patients to Audiovestibular Unit was more or less homogenous all over months of the year in spite of expected higher rate between school-aged children during summer months; this may be due to timing of schooling from the last fourth of year up to the end of the first half of the next year.

It also means that middle-aged patients were predominant during the period of study. In spite of the higher incidence of hearing problems, the old age group reported in a previous study. ${ }^{6}$ In contrast to the previous study, a national household survey to estimate the prevalence and causes of hearing impairment in Egypt, our study was conducted in only one hospital in Cairo. It was observed that the higher the population, the likelihood of getting a better representation of hearing problems and vestibular disorders.

This study revealed that There was no statistically significant difference ( $\mathrm{p}$-value $>0.05$ ) between studied groups regarding age and sex. Thus, gender did not affect the occurrence of hearing loss across different age groups. These findings are consistent with a previous study conducted by Abdel Hamid O et al. ${ }^{6}$

Regarding the main complaint distribution among the studied subjects, hearing loss was the predominance (926 patients) followed by tinnitus (340 patients) followed by earache (219 patients) followed by vertigo (198 patients) then, ear discharge (126 patients) and headache (62 patients); this result was expected because most subjects were referred from ENT Outpatient Clinic. It should be noted that adults and the elderly reported the majority of complaints. Nowaczewska $M$ et al. found that headaches impact tinnitus on many levels and may be an important cofactor for tinnitus subtyping. All tinnitus patients should be screened for headache coexistence. Headache treatment may influence tinnitus frequency and severity. ${ }^{7}$ in contrast to the previous study, Prevalence of Ear Disorders at Rabak City, White Nile Province, Sudan, 2017 revealed five main otological symptoms reported among the study populations, which occur separately or in combination. Most of the ear problems were ear pain $(34.2 \%)^{8}$ 
In our study, CHL was found in 246 patients (representing 13.2\%) belonged to the adult age group, while 124 patients (representing $6.6 \%$ ) were in the child age group; on the other hand, only ten patients (representing $0.5 \%$ ) were above 60 years, and 24patients (representing $1.3 \%$ ) fell under the preschool age groups. Regarding SNHL, 444 patients (representing 23.8\%) belonged to the adult age group, 114 respondents (representing $6.1 \%$ ) were in the child age group, patients 182 (representing $9.7 \%$ ) were above 60 years, and 30 patients (representing $1.6 \%$ ) fell under the preschool age group. Regarding MHL, 200patients (representing 10.7\%) belonged to the adult age group, 22 patients (representing $1.2 \%$ ) were in the child age group, patients 124 (representing $6.6 \%$ ) were above 60 years, and 28 patients (representing 1.4\%) fell under the preschool age groups. There was a statistically significant difference between different HL sides among different age groups with predominant all HL types, specially SNHL in the adult age group and bilateral more than unilateral; This finding was predicted, as adults visited our unit at a higher rate than other age groups. The current study is in contrast to a previous study conducted by Abdel Hamid $\mathrm{O}$ et al. who reported that Conductive hearing loss was found in $64.1 \%$ of the group with hearing loss $(10.3 \%$ of the whole sample), sensorineural hearing loss in $33.5 \%$ (5.4\% of the whole sample) and the mixed type in $2.3 \%\left(0.4 \%\right.$ of the whole sample). ${ }^{6}$

About $63.2 \%$ of studied patients have type (A) tympanogram reflecting normal middle ear pressure, $15.7 \%$ of studied patients have a type (B) tympanogram reflecting mainly otitis media with effusions (OME), and $7.2 \%$ have a type (C) reflecting eustachian tube dysfunctions (ETD). A statistically significant difference was found between different age groups regarding immittancy type with predominant type $\mathrm{b}$ and $\mathrm{c}$ among child and preschool age groups ( $\mathrm{p}$-value $<0.05)$; this means that OME and ETD were more common among child and preschool age groups; this was in agreement with Simon F et al. study who found that Acute otitis media (AOM) and (OME) are very common in young children and OME which persists after the onset of AOM is more frequent than the chronic OME. The highest age-specific incidence for all episodes of AOM is one year of age. AOM and OME are most likely to occur in the winter. The OME risk factors are the first episode of OMA before six months of age, male gender, no breastfeeding, daycare centers, low socio-economic conditions, and familial genetic predisposition. ${ }^{9}$ this finding is also similar to the study published by Absalan A et al. who reported that type $\mathrm{C}$ tympanogram was the most common disorder in child age groups and in both genders and There was a significant decrease of negative pressure incidences in the ear with an increase in age. $^{10}$

There were statistically significant differences between ABR among different age groups with abnormal ABR among the adult age group and predominant abnormal ABR among the preschool and child age group. A newborn with permanent hearing impairment (HI) occurs every 500-1000 births in the general population, which is higher than the frequency of other disorders regularly checked at birth. ${ }^{11}$

Furthermore, in certain higher risk' populations, the incidence could rise to 8-100 cases per 1000 infants. Deafness is significant for public health because of its proclivity for causing sequelae and consequences, for example, irreversible speech and cognitive developmental delays. To avoid these consequences, children with particular risk factors for hearing loss must be identified within 3 months of birth, with a proper diagnosis and early care beginning before the sixth month of life. As a result, newborn hearing screening is the first step in any country for early diagnosis of HL in newborns. ${ }^{12}$

In this study, the highest incidence of vestibular disorders is found in adult group (16.2\%) cases followed by the old age group $(10.8 \%)$ cases then child group (1.2\%) cases. About 308 patients have normal VNG findings, while about 526 patients have abnormal VNG findings. Vertigo is a common untreated ailment that is often associated with substantial handicaps and significant psychological morbidity. The precise cause is frequently unknown. It usually starts in the fourth decade and peaks in the sixth decade. ${ }^{13}$

Adults and the elderly are more likely to experience the vertigo of peripheral origin. In preschool and child groups, sickness is less common .The most common cause of peripheral vertigo was benign paroxysmal positional vertigo (BPPV); These findings corroborate a prior study conducted by Abraham AA et al. ${ }^{14}$ also our findings were in agreement with a previous study conducted on 1,116 patients with ages ranging from 11 to 94 years, including 521 patients $\geq 60$ years. Most patients had at least 1 abnormal result, with only $21 \%$ of patients $\geq 60$ years and $43 \%$ of patients $<60$ years yielding no test abnormalities $(p<0.001)$. Patients $\geq 60$ years of age were more likely to demonstrate abnormalities on saccadic and horizontal tracking eye movements, as well as positional and Dix-Hallpike testing with videonystagmography. ${ }^{15}$

Among the patients studied, $928(49.7 \%)$ received medication, $754(40.4 \%)$ received a hearing and vestibular rehabilitation, and $186(10 \%)$ received surgical intervention. This finding was expected due to the predominance of SNHL type among studied subjects. These findings are consistent with a previous study conducted by Abdel Hamid $\mathrm{O}$ et al., who reported that Individuals found to have hearing loss required different management lines. Most of the group needed medical treatment (39.0\%), and 159 (24.8\%) needed hearing aids: 114 needed bilateral treatment and 45 unilateral. Of those who needed hearing aids before the survey, only $8.8 \%$ (14 out of 159 ) used them. Surgical treatment for hearing loss was needed by 143 of the 641 subjects $(22.3 \%)$ : the commonest indications were middle ear infections and otosclerosis. ${ }^{6}$ 


\section{CONCLUSION}

This study showed that the frequent causes of hearing impairment were as follows: presbycusis, noise exposure, wax, and otitis media. The most common cause of vertigo was (BPPV). The adult and elderly categories had the highest incidence of hearing impairment and vertigo.

\section{REFERENCES}

1. Nieman CL and Oh ES. Hearing Loss. Annals of Internal Medicine. 2020;173(11):81-96.

2. Lew HL, Tanaka C, Pogoda TK, et al. 50 Auditory, Vestibular, and Visual Impairments. In Cifu DX, (Ed). Braddom's Physical Medicine and Rehabilitation (Sixth Edition). Philadelphia: Elsevier. 2021:1101-20.

3. Davies R. Chapter 11 - Audiometry and other hearing tests. In Furman JM, Lempert T, (Eds). Handbook of Clinical Neurology: Elsevier 2016:157-176.

4. Cunningham L and Tucci D. Hearing Loss in Adults. New England Journal of Medicine. 2017;377(25):2465-73.

5. Honaker JA. Diagnostic Vestibular Pocket Guide: Evaluation of Dizziness, Vertigo, and Imbalance: Plural Publishing 2020.

6. Abdel Hamid O, Khatib O, Aly A, et al. Prevalence and patterns of hearing impairment in Egypt: a national household survey. EMHJEastern Mediterranean Health Journal. 2007;13(5):1170-80.

7. Nowaczewska M, Wicinski M, Straburzynski M, et al. The Prevalence of Different Types of Headache in Patients with Subjective Tinnitus and Its Influence on Tinnitus Parameters: A Prospective Clinical Study. Brain Sciences. 2020;10(11):776.

8. Alrayah MJIJo O. Prevalence of Ear Disorders at Rabak City, White Nile Province, Sudan, 2017. International Journal of Otolaryngology Head Neck Surgery. 2018;7(6):375-87.

9. Simon F, Haggard M, Rosenfeld R, et al. International consensus (ICON) on management of otitis media with effusion in children. European annals of otorhinolaryngology, head and neck diseases. 2018;135(1):33-9.

10. Absalan A, Pirasteh I, Dashti Khavidaki GA, et al. A Prevalence Study of Hearing Loss among Primary School Children in the South East of Iran. International Journal of Otolaryngology. $2013 ; 138935$

11. Parab SR, Khan MM, Kulkarni S, et al. Neonatal Screening for Prevalence of Hearing Impairment in Rural Areas. Indian Journal of Otolaryngology and Head \& Neck Surgery. 2018;70(3):380-6.

12. Martines F, Salvago P, Bentivegna D, et al. Audiologic profile of infants at risk: Experience of a Western Sicily tertiary care centre.
International Journal of Pediatric Otorhinolaryngology. 2012;76(9):1285-91.

13. Figtree WVC, Menant JC, Chau AT, et al. Prevalence of Vestibular Disorders in Independent People Over 50 That Experience Dizziness. Front Neurol. 2021;12(709):658053.

14. Abraham AA, Anil MP. Peripheral vertigo--a study of 100 cases: our experience. Journal of Evolution of Medical Dental Sciences. 2014;3(27):7421-7426.

15. Nimmo ZM, Hwa TP, Naples JG, et al. Agerelated Patterns of Vestibular Dysfunction in Dizziness and Imbalance: A Review of Vestibular Testing Results Among 1,116 Patients. Otology \& Neurotology. 2021;42(6). 